\title{
Patria Suave: uma análise das obras de divulgação sobre a história do México publicadas durante as comemorações do Bicentenário
}

\author{
Patria Suave: an Analysis of Works on Mexican History for a General \\ Audience Published During the Bicentennial Celebrations
}

\author{
Luis Guilherme Assis Kalil \\ Igkalil@yahoo.com.br \\ Doutor \\ Universidade Estadual de Campinas \\ Avenida dos Pioneiros, 120/ 57, Condomínio das Gérberas - Villa Flora \\ 13175-668 - Sumaré - SP \\ Brasil
}

\section{Caio Pedrosa da Silva}

caiopedrosa@gmail.com

Doutor

Universidade Estadual de Campinas

Rua João Batista Botelho, 417 - Parque São Domingos

05126-010 - São Paulo - SP

Brasil

\section{Resumo}

Em 2010, o México organizou uma longa série de cerimônias públicas, vídeos, músicas e discursos em comemoração ao Bicentenário de sua Independência e ao Centenário da Revolução Mexicana. O objetivo do presente artigo é analisar de que maneiras determinadas obras de divulgação sobre a história mexicana publicadas durante as celebrações representaram o passado mexicano a partir de dois eixos centrais: o período pré-colombiano e a Revolução Mexicana. Devido à profusão de discursos produzidos no período, centraremos nossa atenção nas obras voltadas ao público não especializado que alcançaram as maiores tiragens dentre as que foram organizadas durante as comemorações do Bicentenário ou mesmo como parte delas.

\section{Palavras-chave}

História da América; Historiografia; México.

\begin{abstract}
In 2010, Mexico organized an extensive series of public ceremonies, videos, songs and speeches on occasion of the Bicentennial celebration of its Independence and of the Centennial celebration of the Mexican Revolution. The aim of this article is to analyze in which ways certain works on Mexican History for general audience published during the celebrations represented the Mexican past with two central axes: the pre-Columbian period and the Mexican Revolution. Due to the profusion of discourses produced in the period, we focus our attention on the works with the largest print run aimed at the non-specialist audience, among all the works organized during the Bicentennial celebrations or as part of them.
\end{abstract}

\section{Keywords}

Latin American History; Historiography; Mexico.

Recebido em: 12/5/2014

Aprovado em: 29/8/2014 
Após alguns segundos de escuridão, a tela projeta uma rápida sucessão de imagens que vão de cidades atuais até antigas construções pré-colombianas, sugerindo uma viagem de volta no tempo. Uma data aparece em destaque: 1.200 a.C. Este é o momento escolhido como início da narrativa que pretende apresentar os principais eventos que caracterizariam a trajetória da história do México.

As enormes cabeças esculpidas pelos olmecas dão lugar a elaboradas construções indígenas, culminando com a imagem da águia com a serpente sobre o nopal; é então que surge uma segunda data na tela: 1325, acompanhada por recriações digitais das construções de Tenochtitlán.

Novo corte. Cenas de caravelas acompanhadas por explosões cenográficas precedem a terceira data destacada: 1521. Rápidas referências ao período colonial são cortadas por sinos e pela imagem do padre Hidalgo, o "pai" da Independência, que indicariam não o início, mas sim uma nova etapa na milenar trajetória do México.

Em seguida, sons de canhões e gritos são interrompidos pela imagem de Benito Juárez e por pombas da paz. A partir de então, encontramo-nos em meio a trens, construções e máquinas. No entanto, a tranquilidade do Vale do México, observado por imponentes vulcões e presente na paisagem pintada por José Maria Velasco Gómez (1840-1912), indica que a pátria, ainda que em processo de modernização, é essencialmente a mesma.

Ruídos de tiros abrem caminho para o terceiro grande evento de ruptura no desenrolar da história pátria: a Revolução. A partir daí, a narrativa prossegue mostrando imagens de personalidades e eventos do passado recente que culminam com a pergunta "¿Qué es México?", respondida por uma sequência de rostos de mexicanos.

A descrição acima se refere à apresentação multimídia 200 años de ser orgullosamente mexicanos, exibida gratuitamente na Cidade do México no dia 5 de maio de 2010. ${ }^{1}$ Formulada a partir de conceitos propostos pelo historiador Enrique Krauze, a obra foi produzida pelo governo federal, que organizou e patrocinou sua exibição nas principais cidades do país ao longo do ano como parte das comemorações do Bicentenário da Independência do México e do Centenário da Revolução Mexicana.

Além dessa apresentação, houve inúmeros outros eventos em comemoração à dupla efeméride: apresentações artísticas, especiais nas emissoras de televisão e rádio, discursos e cerimônias oficiais, paradas militares, inauguração de monumentos ${ }^{2}$ e a exumação dos corpos dos "heróis da Independência", ${ }^{3}$ muitos deles patrocinados pelo governo federal ou estreitamente relacionados a ele.

O campo historiográfico também integrou essas comemorações. Ao longo do ano, dezenas de livros, artigos, ensaios e coletâneas foram produzidos tendo

\footnotetext{
${ }^{1}$ Data em que se comemora a vitória do exército mexicano sobre os franceses na Batalha de Puebla (1862). 2 O principal deles é a Estela de Luz. Atrasos em sua execução, contudo, fizeram com que a obra só fosse concluída em 2012.

3 No dia 30 de maio de 2010, em meio a honras militares, os corpos de 12 líderes do movimento de independência do México foram exumados sob o argumento de que seriam realizados estudos para confirmar a identidade dos restos mortais e sobre as condições de vida de cada um deles.
} 
as duas datas comemorativas e, mais amplamente, a história do México, como ponto de partida para suas reflexões.

Assim como em outros casos, o governo federal também atuou intensamente dentro dos domínios de Clio. O exemplo mais evidente disso foi a republicação póstuma do Álbum de historia de México, na qual o renomado historiador Luis González y González traça pequenos retratos de personagens "relevantes em algum momento da história nacional sem importar suas qualidades morais" (GONZÁLEZ Y GONZÁLEZ 2010, p. 5). Apesar de ter sido composta na década de 1990, essa obra foi selecionada pelo governo mexicano para ser adaptada, renomeada 4 e enviada gratuitamente pelos correios para milhões de lares mexicanos, acompanhada por um exemplar da bandeira nacional. ${ }^{5}$

Um segundo exemplo de atuação do governo federal no campo historiográfico foi a publicação da Historia de México, em esforço conjunto com a Academia Mexicana de História. Organizada em capítulos escritos por reconhecidos historiadores mexicanos, a obra traça, didaticamente, o longo caminho percorrido pelo México desde a migração humana para o Novo Mundo até o século XXI. ${ }^{6}$

Em ambos os casos, as obras contaram não apenas com textos introdutórios assinados pelo então presidente da República, Felipe Calderón Hinojosa, como também foram lançadas em grandes eventos oficiais que integraram as comemorações do Bicentenário, onde foram apontadas como capazes de fortalecer o espírito de unidade e a identidade dos mexicanos (CALDERÓN 2010a; 2010c).

Outra obra que se destacou no período, embora não tenha recebido investimentos diretos por parte do governo federal, foi a Nueva historia general de México, produzida pelo Colegio de México como uma versão inteiramente renovada de seu sucesso editorial Historia general de México, lançado em 1976 e seguidamente republicado.

Ainda que possuam muitas características específicas e até antagônicas (abordadas ao longo do artigo), podemos identificar entre essas obras um aspecto em comum: a tentativa de sintetizar a história do México para um amplo público leitor não especializado no momento em que o país comemorava duas de suas mais importantes efemérides. ${ }^{7}$ Esse objetivo era reforçado pelo baixo custo das edições (ou mesmo a sua gratuidade), pela grande quantidade de exemplares impressos e pela ampla distribuição alcançada. Por isso, tais obras irão balizar nossas reflexões acerca da questão central do presente artigo: de que forma

\footnotetext{
${ }^{4}$ A obra passou a ser intitulada Viaje por la Historia de México.

${ }^{5}$ Além dos mais de 25 milhões de exemplares distribuídos, a obra também foi disponibilizada integralmente no site do governo federal dedicado ao Bicentenário.

${ }^{6}$ Há na obra a indicação de que ela faz parte das atividades que o governo federal organizou em comemoração ao Bicentenário (WOBESER 2010, p. 6). Não por acaso, sua capa exibe a pintura do Vale do México feita por Velasco também presente no vídeo comemorativo citado acima. Para uma análise do conteúdo da coletânea, Cf. KALIL; SILVA 2013.

7 No entanto, cada obra tem uma visão particular sobre qual seria seu público-alvo não especializado. González y González afirma ter pensado nos jovens, ainda que não desmerecesse a leitura por parte dos adultos. Já a Historia de México seria dirigida a "todos os mexicanos". Quanto ao compêndio do Colegio de México, afirma que o intuito da obra era o de ser um livro de cabeceira para qualquer "leitor maduro" interessado pelo passado mexicano (GONZÁLEZ Y GONZÁLEZ 2010, p. 5).
} 
as obras de divulgação publicadas durante ou como parte das comemorações do Bicentenário construíram suas representações sobre o passado "nacional" mexicano tendo em vista um público que transcendia a academia.

Com o intuito de aprofundar nossa reflexão, também utilizaremos outros materiais historiográficos, como coletâneas de artigos publicadas nesse período, voltadas para um público acadêmico (LEYVA 2010; MAYER 2007), e outros compêndios, não vinculados às comemorações, que tratam a história do México das suas "origens" até tempos recentes (ESCALANTE GOZALBO 2004; MEYER; BEEZLEY 2000; VILLEGAS 1973).

No entanto, não foram apenas historiadores profissionais os que deram seu "parecer" sobre o passado mexicano. Filmes, histórias em quadrinhos, músicas, programas televisivos etc., embora nem sempre elaborados a partir das mesmas premissas dos historiadores, também usaram eventos do passado e suas ressonâncias no presente como tema para reflexões sobre o México e sua história. Entre essas produções, destacamos os discursos proferidos por autoridades governamentais durante alguns dos eventos oficiais, bem como livros escritos por especialistas de outras áreas. Esse é o caso de $\mathrm{Ni}$ Independência ni Revolución, obra ilustrada que se define como uma leitura satírica da história mexicana, criada pelo ilustrador Rius (2010) e que também alcançou uma ampla divulgação no período.

Devido à impossibilidade de se analisar todos os períodos da história mexicana (que, como veremos adiante, poderia chegar, para alguns autores, aos milhares de anos), decidimos concentrar nossas atenções em dois momentos específicos, apontados por muitas das obras analisadas como sendo definidores da trajetória nacional: o período pré-hispânico, desde os primeiros grupos humanos a se fixarem na região até o desenvolvimento de uma "civilização mesoamericana", e a Revolução Mexicana. ${ }^{8}$ Os momentos selecionados permitem a análise de dois problemas centrais na tradição historiográfica mexicana e que apareceram com destaque durante o Bicentenário: a questão das "origens" da nação e a pluralidade de posições na história mexicana tendo em vista como são tratados os conflitos entre grupos antagônicos durante a Revolução.

Não é novidade que a narrativa histórica é um componente fundamental do discurso nacional e identitário mexicano. A produção de escritos sobre "a" história do México nos remete ao patriotismo criollo do século XVIII, de autores como o jesuíta Francisco Javier Clavijero, e passa pelas disputas entre as tradições liberais e conservadoras ao longo do século XIX. Com a consolidação do Estado liberal e revolucionário, a narrativa histórica foi usada como elemento de legitimação política das elites governantes naquilo que ficaria conhecido como história "oficial" ou de "bronze", consolidada em monumentos, manuais escolares, entre outros espaços.

\footnotetext{
8 Como pretendemos demonstrar adiante, a Independência do México, um dos objetos centrais das comemorações do Bicentenário, ainda que importante processo de ruptura, não marca o início da história nacional nas obras analisadas. Em linhas gerais, a Independência representaria uma ruptura política, que daria origem a um Estado nacional, formalizando uma nação mexicana dentro de um quadro político moderno e ilustrado que, entretanto, seria resultado de um processo muito anterior.
} 
Essa história "oficial", por sua vez, passou a ser bastante questionada pela historiografia acadêmica a partir de meados do século XX (FLORESCANO 1991). ${ }^{9}$ Contudo, como pretendemos argumentar adiante, ainda que com exceções, alguns de seus elementos permaneceram exercendo um papel determinante dentro das narrativas reproduzidas em obras de divulgação, como os relativos à construção de um passado nacional muito anterior ao processo de independência política e a uma predileção pela identificação de grandes líderes que teriam comandado os rumos dessa nação "milenar".

Acreditamos que as obras de divulgação sejam um dos principais pontos de contato entre a historiografia acadêmica e o público leitor não especializado, o que reforça a sua importância e a necessidade de se refletir sobre essa produção que é, muitas vezes, relegada ao segundo plano.

Nosso objetivo, dessa forma, não é analisar como a "historiografia mexicana"10 retratou ou analisou as comemorações do Bicentenário e suas relações com a história nacional como um todo, mas sim as escolhas realizadas em um grupo específico de obras que buscavam "explicar" - de forma acessível tanto no preço quanto no conteúdo - o passado nacional para um amplo público leitor.

Por fim, consideramos importante realizar duas ressalvas. Embora não representem o todo das publicações lançadas durante as comemorações da dupla efeméride, as obras selecionadas neste artigo se destacam por sua amplíssima distribuição, pela importância dos nomes e instituições envolvidos nas publicações e, ao menos em dois dos casos analisados, pela atuação direta do governo federal.

Além disso, é importante observar que não pretendemos hierarquizar o conteúdo dos textos, identificando formas "melhores" ou mais "corretas" do que outras de se narrar os eventos selecionados. Nosso intuito é observar qual história mexicana e qual México foram apresentados nas obras historiográficas de divulgação produzidas durante ou como parte dos festejos do Bicentenário, ${ }^{11}$ refletindo assim sobre o papel público exercido pela historiografia mexicana nesse momento.

\section{A busca pela origem do México}

Quando se inicia a história do México? Esta pergunta, abordada, ainda que indiretamente, por todas as obras citadas até aqui, foi respondida por boa parte delas como: desde que há humanos nestas terras ou, mais precisamente, desde que eles desenvolveram uma "civilização". A busca por uma origem da nação, tema que remete à historiografia mexicana do século XIX (Cf. FERNANDES 2012), preocupada em construir um passado nacional para o vice-reino recém-independente e marcado por intensos conflitos internos e externos, encontra

\footnotetext{
9 Dois centros de excelência acadêmica em história foram fundados na década de 1940: o Colegio de México (1940) e o Instituto de Investigaciones Históricas da UNAM (1945).

${ }_{10}$ Consideramos problemática a adoção de conceito tão vago e abrangente, pois implicaria a identificação de discursos, posturas e interpretações comuns dentro de uma produção vasta e heterogênea.

11 É importante salientarmos que a própria noção de bicentenário é questionada em algumas das obras abordadas. Para Rius (2010, p. 137), não teria havido "nem independência, nem revolução", o que impediria comemorações em 2010. Já para Enrique Krauze $(2010$, p. 15; 127) havia uma efeméride mais importante do que as duas então celebradas: o "sesquicentenário esquecido" da Reforma.
} 
nessas obras um lugar de destaque. Dessa forma, os primeiros capítulos de todas elas retornam ao período pré-colombiano em busca de algo que pudesse ser identificado como a raiz da qual o México se desenvolveria ao longo dos séculos.

Iniciando nossa análise pela obra de González y González, podemos observar um aspecto enfatizado por muitos autores: a identificação de uma civilização original desenvolvida em solo mexicano que diferenciaria positivamente o passado da região e marcaria a identidade mexicana até o presente. Para esse historiador (2010, p. 6-7), apenas seis partes do mundo teriam conseguido alcançar o estágio "superior" de desenvolvimento. Assim, o México se equipararia à China, Mesopotâmia, Índia, Egito e à região andina como os únicos locais "onde se originou a civilização".

A tentativa de equiparar o passado mexicano a grupos do Velho Mundo considerados avançados já está presente em relatos do período colonial e permanece sendo apontada como base para as reflexões sobre a origem "nobre" do México e de seus habitantes. O capítulo de Miguel León-Portilla (2010, p. 49) na Historia de México é exemplar a esse respeito. Nele, o autor adota o conceito de "civilizações originárias", as únicas seis regiões do mundo (as mesmas apontadas por González y González) que teriam desenvolvido sua civilização de forma independente.

A defesa de uma origem nobre, singular e equivalente ao que é interpretado por esses autores como o que houve de mais desenvolvido entre as primeiras civilizações do mundo - e que deveria ser motivo de orgulho para os mexicanos está presente mesmo em obras que afirmam fornecer uma versão alternativa do passado "nacional", como o livro de Rius. Nele, o escritor e ilustrador afirma que, a despeito dos conflitos que travavam entre si, os diferentes grupos indígenas que habitavam as terras mexicanas teriam criado uma civilização "tão chingona como a egípcia"12 e chegado a superá-la em aspectos como o da construção de pirâmides (RIUS 2010, p. 14-16, grifos nossos).

À identificação de uma civilização original segue-se a busca por um ponto de partida de onde ela teria se disseminado. Retornando à apresentação multimídia descrita no início do texto, percebemos que a data eleita é a de 1.200 a.C., cabendo aos olmecas o papel de "cultura madre". Esse conceito também se faz presente em outras obras, como a de González y González (2010, p. 6-7), para quem esse grupo indígena teria sido o responsável por assentar as bases da Mesoamérica.

Dessa forma, parte-se do princípio de que os grupos indígenas mesoamericanos, por possuírem uma "mãe", compartilhariam características comuns entre si, discerníveis por suas construções, símbolos e crenças religiosas. Dos olmecas, essas características originais teriam percorrido um longo caminho, passando por locais como Teotihuacán e Tula, até alcançarem os astecas, e, destes, teriam se transmitido a todos os mexicanos atuais após o contato com os espanhóis. ${ }^{13}$

\footnotetext{
12 Chingona é um termo de baixo-calão de difícil tradução para o português. Uma tradução aproximada, que mantém a vulgaridade do termo, seria "fodona".

${ }_{13}$ Não por acaso, as duas outras datas selecionadas pelo espetáculo 200 años de ser orgullosamente mexicanos,
} 
Novamente, o texto de León-Portilla é exemplar. Nele, o autor afirma que, a partir de 1.500 a.C., a região olmeca começou a desenvolver uma série de criações artísticas notáveis (como as colossais esculturas de cabeças humanas em basalto, o calendário e a escrita) que irradiaram sua influência para diversos lugares do que hoje se conhece como Mesoamérica. ${ }^{14} \mathrm{~A}$ marcha dessa civilização teria seguido, ainda que com percalços, até as comemorações do Bicentenário, pois haveria uma continuidade incontestável, fundamental para a compreensão do México atual e de seus habitantes. ${ }^{15}$ A visão altamente positiva dada ao conceito de "civilização originária" por parte de León-Portilla faz com que ele tente "justificar" práticas como a dos sacrifícios humanos, vistas por muitos como uma "sombra que obscureceria a grandeza dos mesoamericanos em geral" (WOBESER 2010, p. 46-67).

A identificação de uma civilização original como ponto de partida para a história do México também pode ser observada em outras obras, como as duas versões da Historia mínima de México. Na primeira versão do manual, publicado na década de 1970, Ignacio Bernal afirma que a civilização mesoamericana se iniciara com os olmecas por volta do ano 1.000 a.C. (esta seria, para o autor, a primeira grande época mexicana), e suas características poderiam ser encontradas em muitas partes da Mesoamérica (VILLEGAS 1973, p. 14). Após o declínio olmeca, teriam surgido diferentes tipos de sociedades. Entretanto, diante da impossibilidade de abordar todas elas, o autor decide se ater à que se tornou "mais poderosa" e cujos efeitos ainda estariam presentes entre os atuais mexicanos: a teotihuacana, que herdou características dos olmecas e foi além, construindo uma civilização "completa" como nunca antes teria havido na América (VILLEGAS 1973, p. 18-29).

Processo semelhante encontra-se na Nueva Historia mínima de México, de 2004. Em seu artigo sobre o México antigo, Pablo Escalante Gonzalbo afirma que o "México é muitos Méxicos". Contudo, a escassez de informações sobre muitos desses povos, bem como os limites físicos do livro o obrigavam a recuperar o fio condutor das histórias centrais, hegemônicas, que se encontrariam "no âmbito da civilização mesoamericana", como a dos olmecas e a de Teotihuacán (ESCALANTE GONZALBO 2004, p. 11-20). Podemos observar que, em ambas as versões, a multiplicidade do passado indígena é deixada de lado em prol de uma "marcha da civilização" que parte dos olmecas e segue até o presente.

Como contraponto a essa visão linear e coesa dos caminhos percorridos por uma complexa civilização mexicana, podemos citar as proposições presentes nos artigos iniciais da Nueva historia general de México. Nesta obra, Erik Velásquez García problematiza a noção dos olmecas como "cultura madre". Segundo o autor, a despeito de uma persistente linha de pensamento que atribui a tal grupo

1325 e 1521, referem-se, respectivamente, à fundação de Tenochtitlán pelos astecas e à conquista da mesma cidade por parte dos espanhóis liderados por Hernán Cortés.

${ }^{14}$ Para reforçar seus argumentos, o historiador inseriu dois mapas que indicam o "florescimento das civilizações originárias" e a "irradiação do foco inicial da civilização originária mesoamericana" (WOBESER 2010, p. 47-48).

15 Os argumentos expostos por León-Portilla em seu artigo na Historia de México foram reproduzidos pelo presidente Felipe Calderón em discursos nos que buscava enfatizar a origem nobre e "civilizada" da nação mexicana (CALDERÓN 2010a). 
o "berço" da civilização mesoamericana, novos estudos indicam que muitas das características relacionadas aos olmecas teriam se originado em outras regiões da Mesoamérica, ocupadas por sociedades igualmente complexas (VELÁSQUEZ GARCÍA 2010, p. 39-41).

Da mesma forma, Enrique Nalda, ao abordar o período "clássico" do México antigo, também defende uma interpretação que privilegia a noção de pluralidade. Para ele, o afã de construir uma visão "simplificada" e "coerente" sobre o período fez com que muitos estudiosos identificassem uma história comum aos povos da região mesoamericana, fazendo com que ela passasse a ser vista como uma "totalidade inevitável" com um "emissor central" (os olmecas) que daria coerência ao todo. Ainda segundo Nalda, essa visão do período pré- colombiano traria consigo uma infundada noção de progresso, de acordo com a qual cada novo "filho" da cultura original incorporaria os elementos herdados e os aprimoraria, chegando esse processo a seu ponto máximo com os mexicas e toltecas (VELÁSQUEZ GARCÍA 2010, p. 74).

Contudo, podemos observar que, seja reafirmando ou problematizando a visão de uma cultura mãe, todas as obras analisadas até o momento recuam a origem do México até as primeiras culturas desenvolvidas na região. É interessante compararmos a imagem da origem nacional proposta por esses autores com outras interpretações sobre a história do México. Por exemplo, podemos citar a de The Oxford History of Mexico (MEYER; BEEZLEY 2000). A coletânea de artigos em língua inglesa define a Espanha como o início de sua narrativa. Seguindo esta escolha, o capítulo de abertura ("The Spain that encountered Mexico"), ${ }^{16}$ escrito por Helen Nader, aborda a história mexicana a partir de elementos como o imaginário europeu sobre os contatos medievais com o Oriente, o impacto da pequena era glacial e de epidemias como a da peste negra na Europa medieval, bem como a influência das organizações políticas existentes nas cidades espanholas durante o início da presença europeia no Novo Mundo. Esses conceitos e questões são ignorados ou, ao menos, minimizados pelas publicações mexicanas analisadas.

É evidente que não pretendemos estabelecer constantes, como a forma "mexicana" ou a "estrangeira" de se narrar a história do México, mas sim enfatizar as diferentes possibilidades de se abordar essa questão, bem como as escolhas realizadas por cada um desses autores e as implicações que elas trazem consigo. Com isso, observamos que, ainda que haja exceções (como os dois artigos presentes na Nueva historia general de México), há em boa parte dos compêndios de história do México produzidos nos últimos anos uma tentativa, comum a muitos autores do século XIX, de identificar uma trajetória linear e milenar da história do México.

Apesar de as comemorações girarem em torno dos duzentos anos da Independência, há uma busca por recuar o nascimento da nação até os

${ }_{16}$ No segundo capítulo da coletânea ("The Mexico that Spain encountered"), Susan Schroeder aborda o passado pré-colombiano da região. Contudo, ignora questões como as teorias sobre a origem dos indígenas (constantemente abordada nas obras publicadas em torno do Bicentenário) e centra sua atenção nos três séculos que antecederam o contato dos espanhóis com o Novo Mundo (MEYER; BEEZLEY 2000, p. 47-79). 
primeiros povos que se fixaram nas terras mesoamericanas. Ora em passagens de discursos de Felipe Calderón, para quem a história do país "se funde no tempo" (CALDERÓN 2010b), ora em trechos das obras analisadas, o que se verifica é a construção de um México muito anterior a 1810 (Cf. ESCALANTE GOZALBO 2004, p. 58-61; WOBESER 2010, p. 16; 265). Trata-se de um México que possui uma trajetória que privilegia as relações de troca e as características em comum entre os diferentes grupos indígenas da região - em detrimento de outras leituras, que destacam as diferenças e a multiplicidade de culturas que coabitavam estas terras - e o desenvolvimento progressivo de uma civilização complexa e equiparável às mais desenvolvidas do mundo.

\section{Revolução pacificada}

Quando se analisa a Revolução Mexicana, a continuidade da história pátria é, de saída, um problema, porque, como o próprio nome indica, trata-se de um movimento de ruptura. Ainda assim, contrariando o discurso revolucionário, parte importante da historiografia destacou a Revolução como um movimento essencialmente de continuidade. Nesse sentido, a Revolução se definiria pelo aprofundamento do estatismo centralista do regime de Porfirio Diaz. ${ }^{17}$ Outros historiadores defendem que a Revolução rompeu com a lógica política elitista do regime anterior, trazendo outros grupos sociais para o centro do debate político mesmo que nem sempre como protagonistas. ${ }^{18}$ Além das fraturas historiográficas das quais já demos um exemplo, durante o período revolucionário surgiram diferentes grupos, em geral apelidados a partir do nome de seu respectivo líder (zapatistas, villistas, carrancistas, entre outros), que, além de combaterem o governo de Porfirio Díaz, também se enfrentaram entre si. De certa forma, é um lugar-comum dizer que a Revolução foi um movimento com distintas vertentes e lideranças; o problema é como essa variedade é interpretada em seu conjunto - se é que se aponta um conjunto possível - e na sua relação com seu antes e com seu depois. Felipe Calderón, em seu discurso de 20 de novembro de 2010 - centenário do início da Revolução -, apontou justamente a pluralidade como a maior riqueza da vida democrática conquistada pela Revolução, pois uniria os mexicanos (CALDERÓN 2010c). A pluralidade também é apontada por Álvaro Matute no capítulo dedicado à Revolução Mexicana da Historia de México. Segundo o autor, o chamado de Madero para derrubar o governo de Díaz, em 1910, foi atendido por uma grande variedade de grupos sociais (WOBESER 2010, p. 228). ${ }^{19}$

Apesar disso, não aparecem nas coletâneas reflexões sobre o viés pelo qual a Revolução é abordada. Não há referências a interpretações destoantes a respeito desse evento, especialmente no que se refere a enfoques historiográficos díspares. O mesmo não ocorre nas coletâneas publicadas para

\footnotetext{
17 Porfirio Díaz (1830-1915) foi um general liberal que, nas décadas de 1850 e 1860, combateu grupos conservadores mexicanos e o Império de Maximiliano de Habsburgo estabelecido no México. Em 1876 Díaz assumiu a presidência e governou, com um pequeno intervalo, entre 1880-1884, até a eclosão da Revolução Mexicana.

18 Para aprofundar o debate, entre outros, Cf. XAVIER-GUERRA 1988 e KNIGHT 1985.

19 Na primeira versão do texto da Historia mínima de México, Eduardo Blanquel indica que a Revolução rompera com a homogeneidade imposta pelo porfiriato (VILLEGAS 1973, p. 142).
} 
o público especializado. Além de apresentarem artigos com visões diferentes a respeito da Revolução, apresentam também textos específicos sobre historiografia e interpretações. ${ }^{20}$

Escapar do dissenso quando se trata da Revolução é, como dissemos, muito difícil. Embora não apareçam os conflitos historiográficos, nas coletâneas estão presentes os conflitos entre grupos revolucionários. Veremos a seguir como os diferentes autores lidam com essa "pluralidade" de uma ou de outra forma assumida e, ao mesmo tempo, incluem a Revolução na continuidade da história nacional.

O texto de González y González apresenta uma sequência de páginas a respeito da Revolução, todas elas seguindo o estilo da publicação, com um breve resumo histórico do período e pequenas biografias de personagens considerados importantes. Alguns nomes recebem maior atenção, com uma biografia no alto da página, como é o caso de Francisco I. Madero; sua biografia é introduzida com as seguintes palavras: "Presidente do México chamado de Apóstolo da Democracia" (GONZÁLEZ Y GONZÁLEZ 2010, p. 51). Quanto a Francisco Villa, são destacados o que seriam seus dotes naturais como estrategista e militar (GONZÁLEZ Y GONZÁLEZ 2010, p. 52). As biografias mais descritivas e distanciadas de alguns personagens ${ }^{21}$ destoam daquela dedicada ao general revolucionário e presidente (1921-1924) Álvaro Obregón, antes um brilhante militar e agora um político perspicaz, que se dedicou à pacificação e reconstrução do país (GONZÁLEZ Y GONZÁLEZ 2010, p. 55). O escritor Martin Luiz Guzmán e ex-revolucionário villista, autor dos romances históricos La sombra del caudillo e El águila y la serpiente, também é enaltecido nas páginas de González. Segundo o historiador (GONZÁLEZ Y GONZÁLEZ 2010, p. 55), Guzmán fez vivos testemunhos e plasmou em seus romances a crueldade da luta e a ambição desmedida pelo poder. Não há, contudo, referência ao fato de o ambicioso e cruel caudillo do romance de Guzmán ter sido inspirado em Obregón.

Alan Knight descreve certo hábito de alguns historiadores de dividirem os presidentes mexicanos entre os bons, os maus e os feios (MAYER 2007, p. 298). O texto de Matute confirma a possibilidade de organizar um casting de faroeste italiano com os presidentes mexicanos, mesmo que o formato do texto permita ora ou outra reflexões um pouco mais aprofundadas. Obregón é forte candidato para representar o bom - visto que teria pacificado o país, acabando com a dissidência (WOBESER 2010, p. 240). Mas Adolfo de la Huerta disputaria o papel, pois sua curta estadia no palácio presidencial é descrita como "excepcional", dada sua capacidade de negociação com grupos rivais (WOBESER 2010, p. 236). Plutarco Elías Calles (1924-1928), devido ao seu "radicalismo" anticlerical que dividiu o país durante a Cristera, representa o mau. No pouco honroso papel de feio está escalado Ortiz Rubio, que até tentou

\footnotetext{
${ }^{20}$ Sobre a Revolução Mexicana, ver MAYER 2007, p. 409-420. Na coletânea de Leyva (2010), a presença do tema está mais difusa, distribuída entre vários artigos.

${ }^{21}$ Sobre Pascual Orozco, por exemplo, a obra aponta que ele primeiramente apoiou e depois rompeu com Madero, "acusando-o de não cumprir o Plan de San Luis de Potosí". Nada é dito sobre qual aspecto do Plan não foi cumprido ou sobre quais eram as reivindicações de Orozco que o diferenciavam de Madero (GONZÁLEZ Y GONZÁLEZ 2010, p. 50).
} 
imprimir traços técnicos ao seu governo, porém não fez nada digno de menção, sendo um homem de "caráter débil" (WOBESER 2010, p. 243-245). O enfoque nos grandes homens ocorre no capítulo de Matute, especialmente para o período a partir da Constituição de 1917, que marca o início de governos revolucionários institucionalmente constituídos. Antes disso, encontramos questões a respeito das ideias dos distintos grupos revolucionários e das suas origens abordadas de maneira rápida e resumida.

Também no livro pretensamente cômico e "politicamente incorreto" do cartunista Rius, são as lideranças que fazem a história, ainda que o autor se coloque na posição de defensor das classes pobres, especialmente dos indígenas - que, para ele, possuiriam uma "mexicanidade" maior que os demais. Porém, em sua obra, as classes populares são as grandes vítimas da história mexicana. Segundo o autor, todas as tentativas de transformação terminam falidas, inclusive a Independência e a Revolução. As histórias da Independência e da Revolução são resumidas ao movimento de seus líderes; alguns deles seriam genuinamente defensores dos interesses populares (como Hidalgo e Cárdenas), enquanto a maioria não passaria de novas versões das elites anteriores. Nesse sentido, aqui encontramos mais "maus" que nas coletâneas, sejam eles Santa Anna, Carranza, Calles, Salinas de Gortari ou qualquer um identificado como conservador. Já o "povo" mexicano - o "nós" do qual o branco e loiro Rius faria parte por ter sido amamentado por uma indígena 22 -, ainda que festejado como verdadeiro valor nacional, diante da história contada no livro é um sujeito inerme, sempre necessitando de lideranças que o guiem, o chamem para a luta e às vezes até o enganem. Em um dos momentos mais preciosos do texto de Rius, o esperto padre Hidalgo, aqui um personagem mais iluminista que Voltaire, notando o poder manipulador da fé, conseguiu um estandarte da Virgem de Guadalupe para atrair os indígenas para a luta independentista (RIUS 2010, p. 52).

Nesse sentido, resulta útil pensarmos como são tratadas as figuras de Emiliano Zapata e Francisco Villa, líderes da vertente "popular" da Revolução. Ambos aparecem nas coletâneas de forma rápida e sem o mesmo destaque dos seus rivais revolucionários constitucionalistas (Obregón, Carranza e os presidentes das décadas seguintes). Zapata recebe um pouco mais de atenção no que se refere ao caráter ideológico das suas requisições por reforma agrária, embora não seja lembrado como grande caudillo militar. No caso de Villa acontece o oposto: seus dotes militares são exaltados ao passo que as motivações específicas da sua luta, aquilo que o diferenciaria dos demais exércitos revolucionários, aparecem pouco - ainda que seu caráter "popular" seja notado (GONZÁLEZ Y GONZÁLEZ 2010, p. 52; WOBESER 2010, p. 228-233).

Atentemos para como González y González descreve a disputa entre villistas/ zapatistas e constitucionalistas. Segundo o autor, prontamente teriam surgido discórdias entre os principais chefes revolucionários: Zapata e Villa exigiram uma solução imediata às demandas agrárias e populares, enquanto Carranza e 
Obregón, as duas principais lideranças constitucionalistas, optaram pela criação de um governo estável e soberano baseado no cumprimento das leis (GONZÁLEZ Y GONZÁLEZ 2010, p. 53). Essa pequena passagem é uma das raras ocasiões em que aparece algum tipo de referência à diferença de concepção sobre a Revolução entre os grupos em disputa. Nas pequenas biografias, é possível pensá-las como lideranças complementares, já que são omitidos dados, por exemplo, sobre os mandatários das mortes de Zapata e Villa. À menção das mortes segue uma espécie de lamento a respeito do "caos" criado pelos dois "bandos". A oposição entre o setor popular e o constitucionalista da Revolução é bastante simples: enquanto os populares "exigem", os constitucionalistas "optam"; os populares defendem demandas agrárias, e os constitucionalistas, a estabilidade, a soberania e as leis. Os grupos de Zapata e Villa, derrotados por Carranza e Obregón, parecem se opor à ordem, ou ao menos não se preocupariam com a organização de um regime estável (GONZÁLEZ Y GONZÁLEZ 2010, p. 53). O trecho se assemelha ao de Álvaro Matute, que, ao tratar das disputas entre grupos revolucionários na década de 1920, também destaca o papel unificador dos governantes que dominaram a política mexicana do período (WOBESER 2010, p. 240).

Enquanto no texto de Rius os elogios às lideranças giram em torno da ligação do líder com uma "causa popular" permanente na história mexicana, nas coletâneas historiográficas de divulgação os elogios em geral se direcionam aos méritos militares dos personagens, ou, então, a suas características como lideranças estabilizadoras e pacificadoras. As disputas de interesses, a 80 pluralidade da Revolução, são meros empecilhos para a estabilização do México, especialmente a partir do momento em que há um Estado controlado por um dos grupos revolucionários.

A pacificação das divisões fica clara na abordagem de Álvaro Matute sobre o conflito religioso. O autor afirma que, depois dos acordos entre a Igreja Católica e o Estado mexicano, que colocaram fim à Guerra Cristera (1926-1929), a "normalidade" das práticas religiosas foi um fato (WOBESER 2010, p. 244). Com os acordos, as atividades religiosas, suspensas pela Igreja em protesto contra a legislação anticlerical aplicada pelo governo mexicano em 1926, voltaram a ser realizadas. No entanto, não faltam referências historiográficas aos conflitos entre revolucionários e católicos na década de 1930. Os trabalhos de Adrián Bantjes, para destacar apenas um dos historiadores que trata do tema, apontam especificidades e complexidades da questão religiosa durante o período revolucionário que não aparecem nas amenas histórias das coletâneas. ${ }^{23}$ O lugar das religiões no México foi uma questão debatida continuamente desde a Independência até, poderíamos dizer, hoje. Entender a lógica e as atividades de anticlericalismos, catolicismos e protestantismos no México é um caminho para compreender uma pluralidade religiosa que constituiu a história do país e que vai além da ideia de uma matriz cristã "gravada na alma" do povo mexicano "desde o século XVI" (KRAUZE 2010, p. 29).

\footnotetext{
${ }^{23}$ Segundo Bantjes (1997, p. 92-93), a descristianização da sociedade mexicana, nos termos nem sempre claros dos revolucionários do México, foi um dos projetos da Revolução. Essa ideia também está presente em um artigo do próprio Álvaro Matute, escrito para o público especializado (SAVARINO 2008, p. 29-38).
} 
Nessa revolução, que, desde o princípio, anseia a estabilidade de um regime coeso, os "derrotados" - "derrota" no sentido de não terem governado o país - são atropelados por um discurso nacional linear centrado no Estado. Mas não somente eles. Nos textos de González y González e Matute, outra questão também fica sombreada pela ênfase na estabilização e pacificação: os aspectos de rompimento, principalmente, mas também os de continuidade com o porfiriato.

Nesse sentido, a diferença com o capítulo de Garciadiego e Ficker em Nueva historia general de México é chamativa. Os autores recuperam o sentido do termo "revolução" como uma mudança transformadora, indicando quais foram as transformações pelas quais o país passou durante a Revolução Mexicana. Para esses autores, a Revolução modificou "inquestionavelmente" a estrutura social do porfiriato (VELÁSQUEZ GARCÍA 2010, p. 581). ${ }^{24}$ Embora não encontremos no capítulo um estudo aprofundado sobre as motivações do engajamento popular na Revolução, ${ }^{25}$ os historiadores fazem pequenos apanhados explicativos que auxiliam o público a fazer uma leitura que possa ir além da citação de fatos e feitos de grandes personagens.

Uma diferença importante quanto aos textos de Matute e González é o balanço feito a respeito dos problemas econômicos do país durante os anos da revolução armada (década de 1910). Afastando-se da ideia de uma desordem generalizada no período revolucionário, ${ }^{26}$ Garciadiego e Ficker dedicam um aparte a essa questão - lembremos que, neste livro, os capítulos sobre a Revolução são muito mais volumosos - com o qual tentam desfazer a ideia de "caos" generalizado, apontando que não houve uma destruição total do equipamento produtivo do país, mas modificações importantes na atividade econômica que se vinculou à luta armada (VELÁSQUEZ GARCÍA 2010, p. 567-577).

No capítulo seguinte da Nueva historia general de México, "La Construcción del nuevo Estado, 1920-1945", de Luis Aboites e Engracia Loyo, dedicado ao período de 1920-1945, o enfoque sobre o Estado fica evidente já no título. Contudo, não se estabelece uma oposição entre caos e ordem, pacificação e guerra, como nas demais obras. O Estado que se formou no período da Revolução foi resultado de um dos projetos revolucionários e não do único possível diante do caos revolucionário. Governantes como Calles e Obregón aparecem em muitos momentos tendo de enfrentar distintas forças sociais do país, como a oposição interna - rivais revolucionários - e externa - católicos. Segundo os autores, o Estado formado a partir da Revolução se caracteriza pelo seu poder centralizador e autoritário, dominado pelo Partido Revolucionário, e pelo modelo econômico apoiado na propriedade privada e na crescente classe empresarial (VELÁSQUEZ GARCÍA 2010, p. 648-649).

\footnotetext{
${ }^{24}$ A questão da ruptura é uma marca também da análise de Garciadiego da Revolução Mexicana na Nueva História mínima de México (ESCALANTE GOZALBO 2004, p. 225).

${ }^{25}$ Ainda que apontem "diferenças essenciais", os historiadores acabam não dedicando explicações às distinções entre os grupos revolucionários (VELÁSQUEZ GARCÍA 2010, p. 556).

26 Matute (WOBESER 2010, p. 232) e González y González (2010, p. 53) afirmam que o campo mexicano estava cheio de bandoleiros que assolavam e destruíam povoados e que, no país, vivia-se um "caos" durante as lutas revolucionárias.
} 


\section{Considerações finais}

A análise das representações sobre o passado pré-hispânico e sobre o período da Revolução mexicana presentes nas obras de divulgação sobre a história do México publicadas durante o Bicentenário permitem a identificação de alguns elementos em comum. Em primeiro lugar, podemos observar o que Marc Bloch definiu como o "ídolo das origens" que, muitas vezes, acaba se entrelaçando com a "mania do julgamento" e trazendo consigo a noção de que "as origens são um começo que explica" (BLOCH 2001, p. 56-58).

Essa preocupação com as raízes milenares da identidade nacional, que já despertava intensos debates desde finais do século XVIII, permaneceu como um elemento central em várias das reflexões que permearam as comemorações da dupla efeméride. Ainda que alguns textos questionem a visão dos olmecas como "cultura madre" e a noção de uma marcha linear da civilização, o ídolo descrito por Bloch permanece intacto em boa parte dos casos analisados.

A Independência, evento central nas comemorações do Bicentenário, não ocupa o espaço de origem primordial da nação nas coletâneas analisadas. Ao enfatizarem as continuidades e rupturas entre o regime colonial e independente, essas obras, guardadas as proporções e formatos dos textos, aproximam-se da interpretação identificada por Elías J. Paltí a respeito da produção historiográfica mais recente sobre o período. ${ }^{27} \mathrm{~A}$ origem da nação pode não estar na Independência, mas segue presente a ideia de origem, deslocada para um passado remoto, como fundamental para a história nacional.

$O$ pequeno espaço dedicado à problematização de conceitos como o de "México" e de "mexicano", bem como a análise de diferentes interpretações sobre eventos ou personagens históricos, reforçam uma longa trajetória de construção do México como uma nação atemporal. ${ }^{28}$

A identificação de uma origem traz consigo a noção de identidade e, ao mesmo tempo, de alteridade. Assim, o passado mexicano reproduzido nas obras analisadas não se confunde com os de outros povos ou países americanos, sendo equiparado, quando muito, apenas às outras poucas "civilizações originárias".

Outro elemento em comum que podemos observar entre as obras é o da identificação da trajetória do México com a atuação de grandes personagens. Nesse sentido, com certas exceções (como o livro organizado pelo Colegio de México), tanto as obras de divulgação quanto leituras que se propõem alternativas ou iconoclastas, como a obra de Rius, trabalham com a mesma concepção de história como uma longa sucessão de líderes (sejam eles indígenas pré-colombianos, vice-reis, presidentes ou lideranças políticas dos mais variados matizes) que ditam os rumos de uma nação mexicana atemporal. Não há uma

\footnotetext{
27 Para Paltí, a historiografia sobre os movimentos de independência no México encontrou nas últimas décadas certa unanimidade no que se refere à crítica às perspectivas românticas nacionalistas surgidas no século XIX que, em uma leitura teleológica, centravam o estudo da Independência no seu ponto de chegada: a nação (LEYVA 2010, p. 174). Já o livro de González y González (2010, p 29) se aproximaria mais de uma visão romântica tradicional da independência ao afirmar que os três séculos de domínio espanhol deram origem a uma "nova nação".

${ }^{28}$ Como apontado por Benedict Anderson (2008, p. 38), esse processo não se restringe ao México, mas foi e, em alguns casos, continua sendo reproduzido em vários países por construções do passado que visam edificar uma imagem de uma comunidade nacional.
} 
reflexão sobre o processo de construção do passado nacional em si, mas sim uma disputa em torno dos homens, eventos e ideias que seriam ou não dignos de fazer parte do panteão nacional. ${ }^{29}$ Dessa forma, podemos observar que há nessas obras de divulgação uma continuidade marcante com uma visão de história política como a trajetória dos grandes líderes, processo esse que fica evidente seja na busca pela raiz da civilização, seja nas divisões dos presidentes entre "bons" e "maus", ou nas mais variadas posições sobre quais seriam os principais líderes da Independência ou da Revolução.

Durante a segunda metade do século $X X$, a história política passou a ser repensada a partir de questões como o papel da participação popular e a forma como se dava a comunicação política. A utilização do vago, porém útil, conceito de cultura política fez com que os bares, igrejas e praças passassem a ser vistos como lugares da política assim como os palácios e tribunas. Com isso, o Estado e as lideranças, ainda que fundamentais, deixam de ser o eixo hegemônico. Retornando às obras analisadas, observamos que essa tendência de renovação dos estudos da história política, ${ }^{30}$ com raras exceções, ${ }^{31}$ passa longe das análises sobre o passado mexicano presentes nos casos analisados. ${ }^{32}$ Assim, o caudillismo ou o caciquismo, por exemplo, são vistos como o motor da narração histórica e não como um tema ou conceito capaz de produzir uma reflexão histórica sobre determinada cultura política.

Por fim, observamos que a ideia de uma trajetória linear e particular de um México guiado por grandes líderes está atrelada à visão de uma história que privilegia as continuidades em detrimento dos conflitos, o que poderíamos denominar como uma história "suave". ${ }^{33}$ Como vimos nas abordagens da Revolução Mexicana, por exemplo, muitos dos autores analisados enfatizam a importância da pluralidade, mas relutam em incluir os conflitos como parte da história da nação. ${ }^{34}$

É evidente que não podemos deixar de ter em mente as especificidades de cada uma das obras e dos interlocutores que pretendem atingir, sejam eles "leitores maduros", jovens leitores ou mesmo todos os mexicanos. Por outro

\footnotetext{
${ }_{29}$ Como exemplo, podemos citar o papel central atribuído a Lazaro Cárdenas na obra de Rius, enquanto na Historia de México e na obra de González y González a ênfase recai sobre Obregón, descrito como um pacificador. ${ }^{30}$ A renovação da história política a que nos referimos foi uma movimentação historiográfica que se deu em diferentes sentidos e por diversos autores que buscaram pensar a análise política para a história. Entre outros, podemos citar Remond e Furet na França e Skinner, Pocock e os representantes do contextualismo linguístico na Inglaterra. No México, as crônicas de Carlos Monsiváis sobre as dinâmicas de grupos urbanos, ainda que não estritamente historiográficas ou políticas, são exemplo de uma visão sobre a sociedade que vai além do ponto de vista somente do Estado e de suas lideranças. Para uma interpretação das mudanças na história política durante o século XX, ver ROSANVALLON 2010.

31 O texto Nueva historia general de México, mais longo e aprofundado, destoa neste ponto ao produzir mais explicações ainda que sem uma reflexão definida sobre a "operação histórica" (VELÁSQUEZ GARCÍA 2010).

32 Esta tendência de renovação, no entanto, ocupa papel central dentro da produção historiográfica mexicana atual, que apresenta leituras e interpretações inovadoras, algumas delas produzidas pelos próprios autores de textos presentes nas obras de divulgação analisadas. Porém, em geral, esses textos se restringem ao público especializado. Um exemplo, entre vários outros, da riqueza e variedade desta historiografia é a coletânea organizada por Leyva (2010) sobre temas relacionados à história do México independente.

33 A referência a uma pátria "suave" está presente num poema de Ramón Lopez Velarde; partes do conteúdo desse poema foram projetadas no vídeo 200 años de ser orgullosamente mexicanos.

${ }^{34}$ Essa visão fica evidente não apenas nos livros promovidos (WOBESER 2010) ou distribuídos (GONZÁLEZ Y GONZÁLEZ 2010) pelo governo federal, mas também em muitos dos eventos e discursos proferidos durante as comemorações. Não por acaso, a Estela de Luz foi erigida no Paseo de la Reforma, continuando um secular processo de construção da memória nacional (Cf. KALIL; SILVA 2013)
} 
lado, referências à falta de espaço ou a busca por um público mais amplo não podem ser apontadas como argumentos para discursos que reproduzem uma leitura unívoca e "suave" da história nacional. Como Michel de Certeau (1982, p. 66-67) nos alerta, ligar ideias a lugares é o gesto do historiador. O processo de produção da história não está descolado de relações de poder que definem a relevância de determinados temas e eventos em detrimento de outros. Os textos publicados com apoio do governo federal optam por não apontar conflitos, sejam eles teóricos ou em relação a eventos do passado mexicano. ${ }^{35}$ No entanto, ainda que não explicitada, a seleção de personagens e acontecimentos que seriam representativos do passado nacional implica uma série de posicionamentos e silêncios.

Acreditamos que a crítica, o debate de ideias e as interpretações sobre o passado, e não somente a elaboração de uma sequência linear e coerente de fatos e o enaltecimento de personagens, são parte essencial da "operação histórica" como discurso que pode integrar o debate público em sociedades plurais. Apresentar o passado sem conflitos contrasta com o presente mexicano, marcado por divisões políticas, sociais e culturais que certamente estão presentes no cotidiano de seus habitantes - afinal, o público-alvo almejado, ao menos retoricamente, por essas obras. Dessa forma, podemos concluir retornando à apresentação 200 años de ser orgullosamente mexicano para ressaltar a relevância e a necessidade constante de se refazer a pergunta que luziu na tela pouco antes do final do espetáculo: "¿Qué es México?".

\section{Referências bibliográficas}

ANDERSON, Benedict. Comunidades imaginadas: reflexões sobre a origem e a difusão do nacionalismo. São Paulo: Cia das Letras, 2008.

BANTJES, Adrián. Idolatry and Iconoclasm in Revolutionary Mexico: The DeChristianization Campaigns 1929-1940. Mexican Studies/Estudios Mexicanos, v. 13, n. 1, p. 87-120, 1997.

BLOCH, Marc. Apologia da história, ou o ofício do historiador. Rio de Janeiro: Jorge Zahar, 2001.

CERTEAU, Michel de. Escrita da História. Rio de Janeiro: Forense Universitária, 1982.

CALDERÓN, Felipe. Discurso - 23/04/2010.

Discurso - 05/05/2010. Disponível em: http://calderon.presidencia. gob.mx/prensa/discursos. Acesso em: 06 fev. 2014.

Discurso - 28/06/2010. Disponível em: http://calderon.presidencia. gob.mx/prensa/discursos. Acesso em: 06 fev. 2014.

\footnotetext{
35 Por outro lado, obras como México en tres momentos foram criticadas no sentido oposto: por estarem demasiadamente centradas em debates teóricos acadêmicos. Para Enrique Krauze (2010, p. 48), essa obra mostra a fragilidade da história acadêmica atual, que teria se tornado um discurso teorizante de colegas falando para e sobre colegas, com enfadonhos debates historiográficos e teóricos.
} 
ESCALANTE GOZALBO, Pablo et al. Nueva historia mínima de México. México: El Colegio de México, 2004.

FERNANDES, Luiz Estevam de Oliveira. Patria Mestiza: a invenção do passado nacional mexicano (séc. XVIII e XIX). Jundiaí: Paco, 2012.

FLORESCANO, Enrique. El Nuevo Pasado Mexicano. México: Cal y arena, 1991. GONZÁLEZ Y GONZÁLEZ, Luis. Viaje por la Historia de México. México: SEP, 2009.

KALIL, Luis Guilherme Assis; SILVA, Caio Pedrosa da. Resenha de Historia de México. Varia História, v. 29, n. 49, p. 361-365, 2013.

KRAUZE, Enrique. De héroes y mitos. México: Tusquets, 2010.

LEYVA, Gustavo et al. Independencia y Revolución: pasado, presente y futuro. México: FCE/UAM, 2010.

MAYER, Alicia (coord.). México entre dos momentos: hacia la conmemoración del Bicentenario de la Independencia y del Centenario de la Revolución Mexicana. México: UNAM, 2007.

MEYER, Michael C.; BEEZLEY, William H. (ed.). The Oxford history of Mexico. New York: Oxford University Press, 2000.

KNIGHT, Alan. The Myth of the Revolution. Past \& Present, v. 209, p. 223$273, .2010$.

. Caudillos y Campesinos en el México revolucionario, 1910-1917. In: BRADING, David (comp.). Caudillos y campesinos en la Revolución Mexicana. México: FCE, 1985 [1980], p. 32-85.

RIUS, Eduardo del Rio. 2010, ni independencia, ni revolución. México: Planeta, 2010.

ROSANVAlLON, Pierre. Por uma história do político. São Paulo: Alameda, 2010.

SAVARINO, Franco; MUTOLO, Andrea (coords). El anticlericalismo en México. México: Porrúa, 2008.

VELÁSQUEZ GARCÍA, Erik et al. Nueva historia general de México. México: El Colegio de México, 2010.

VILLEGAS, Daniel Cosío et al. Historia mínima de México. México: El Colegio de México, 1973.

XAVIER-GUERRA, François. México: del Antiguo Régimen a la Revolución. México: FCE, 1988.

WOBESER, Gisela von (coord.). Historia de México. México: FCE/SEP/Academia Mexicana de Historia, 2010. 